\title{
Morfologia dos pré-estômagos e de papilas ruminais de cordeiras Santa Inês em crescimento submetidas a dois planos nutricionais ${ }^{1}$
}

\author{
Luigi F.L. Cavalcanti ${ }^{2 *}$, Iran Borges², Vandenberg L. Silva ${ }^{2}$, Fredson V. Silva ${ }^{2}$, Hemilly \\ C.M. Sá ${ }^{2}$, Isabella C.F. Maciel ${ }^{2}$, Fabiane A.P. Paula ${ }^{2}$ e Emmanuel H.O. Costa ${ }^{2}$
}

\begin{abstract}
Cavalcanti L.F.L., Borges I., Silva V.L., Silva F.V., Sá H.C.M., Maciel I.C.F., Paula F.A.P. \& Costa E.H.O. 2014. [Morphology of pre-stomach and ruminal papillae of growing Santa Inês female lambs under two nutritional schemes.] Morfologia dos pré-estômagos e de papilas ruminais de cordeiras Santa Inês em crescimento submetidas a dois planos nutricionais. Pesquisa Veterinária Brasileira 34(4):374-380. Departamento de Zootecnia, Escola de Veterinária, Universidade Federal de Minas Gerais, Av. Presidente Antônio Carlos 6627, Belo Horizonte, MG 30123-970, Brazil. E-mail: luigicavalcanti22@gmail.com

For the evaluation of nutritional schemes and change on the pre-stomach morphology and quantification of rumen papillae, 36 Santa Inês female lambs were submitted to two nutritional schemes (ad libitum or restrict) and slaughtered with different live weights (20, 30 or $40 \mathrm{~kg}$ ) in a completely randomized factorial design $2 \times 3$. After slaughter, the viscera were weighed empty and their volume was measured. Samples of ruminal wall from the cranial and ventral sacs were collected and with a stereomicroscope photographed and analyzed regarding height, basal width, area, papillae per $\mathrm{cm}^{2}$ and absorptive area per $\mathrm{cm}^{2}$. The results were submitted to analyses of variance and the means were compared by Student Newman Keuls test. The different nutritional schemes did not influence the weight of rumen, reticulum or omasum $(\mathrm{P}>0.05)$, although, growth of the viscera was observed by increase in live weight. The viscera volume was affected by live weight, and smaller volume was observed in the animals fed ad libitum diet $(\mathrm{P}<0.10)$. The number of papillae per $\mathrm{cm}^{2}$ was reduced by the increase in live weight. Height and area of papillae were larger in heavier animals. The nutritional scheme only affected height and area of papillae of the cranial sac. The absorptive area was not affected by the treatments. Different nutritional schemes and live weights affect the pre-stomach morphology of Santa Ines female lambs.
\end{abstract}

INDEX TERMS: Nutrition, sheep, rumen, ruminal papillae, viscera.

RESUMO.- Para se avaliar o efeito do plano nutricional e crescimento sobre a massa dos pré-estômagos, morfologia e quantificação de papilas ruminais, trinta e seis cordeiras da raça Santa Inês foram submetidas a dois planos nutricionais (ad libitum ou restrito) sendo abatidas em diferentes pesos vivo $(20,30$ ou $40 \mathrm{~kg}$ de peso vivo), em um delineamento inteiramente casualizado balanceado em arranjo fatorial $2 \times 3$. Feito o abate, as vísceras foram pesadas livres de seu conteúdo em seguida mediu-se o volume de repleção

\footnotetext{
${ }^{1}$ Recebido em 19 de setembro de 2013.

Aceito para publicação em 18 de março de 2014.

${ }^{2}$ Departamento de Zootecnia, Escola de Veterinária, Universidade Federal de Minas Gerais (UFMG), Avenida Antônio Carlos 6627, Bairro Pampulha, Belo Horizonte, MG 31270-901, Brasil. *Autor para correspondência: luigicavalcanti22@gmail.com
}

do rúmen e retículo. Amostras do tecido ruminal oriundas dos sacos cranial e ventral foram coletadas para posteriormente serem realizadas com auxílio de lupa estereoscópica as medidas morfométricas das papilas ruminais, altura, largura da base, área, papilas por $\mathrm{cm}^{2} \mathrm{e}$ área absortiva por $\mathrm{cm}^{2}$. Os resultados obtidos foram submetidos a análise de variância e as médias resultantes por tratamento foram comparadas por meio de teste de Student Newmann Keuls. Os diferentes planos nutricionais não influenciaram a massa das vísceras rúmen, retículo e omaso $(\mathrm{P}>0,05)$, no entanto, observou-se crescimento dessas vísceras em função do aumento do peso ao abate. 0 volume dessas vísceras foi afetado pelo peso ao abate, e observou-se menores volumes para animais com alimentação ad libitum $(\mathrm{P}<0,10)$. 0 número de papilas por $\mathrm{cm}^{2}$ foi reduzido com o aumento do 
peso ao abate, sendo que altura e área foram aumentadas quando em pesos maiores. 0 plano nutricional afetou apenas a área e altura das papilas ruminais oriundas do saco cranial. A área absortiva não foi afetada pelos tratamentos. Plano nutricional e diferentes pesos vivos influenciam a morfologia dos pré-estômagos de cordeiras da raça Santa Inês.

TERMOS DE INDEXAÇÃO: Nutrição, ovinos, rúmen, papilas ruminais, vísceras.

\section{INTRODUÇÃO}

A fase de crescimento representa a etapa da vida de qualquer ser vivo onde existe incremento de peso e tamanho (Widdowson 1980), sendo determinado o fenótipo maturo deste organismo. É, portanto, um momento crucial quando se pensa em animais de produção, principalmente no que tange a matrizes e reprodutores, uma vez que serão animais explorados quando em sua maturidade fisiológica.

0 crescimento, no entanto, é afetado por diversos fatores ambientais, entre eles a alimentação. Animais em planos nutricionais inferiores à sua exigência tendem a não expressar todo seu potencial genético, atingindo pesos inferiores àquele programado geneticamente. 0 desconhecimento dos requisitos reais de um determinado ecótipo pode levar à super ou subestimação dos mesmos, redundando em desempenhos atípicos (NRC 2007).

Assim como a aparência externa de animais, o crescimento visceral sofre marcado efeito do plano nutricional, principalmente naqueles tecidos que estão diretamente associados a absorção e metabolização primária dos compostos absorvidos, notoriamente, o trato gastrointestinal e o fígado, sendo relatado efeito da restrição nutricional sobre a morfo-fisiologia visceral (Scheaffer et al. 2004a,b, Macedo Júnior 2008). Em animais da subordem Ruminantia, as câmaras fermentativas pré-estomacais são geralmente forradas por um epitélio típico, formado por papilas. Essas estruturas especializadas são afetadas pela dieta e manejo alimentar (Tamate et al. 1962, Sutton et al. 1963a, 1963b, Lane \& Jesse 1997, Baldwin 2000). Scocco et al. (2007) demonstraram o efeito da sazonalidade anual sobre a qualidade do alimento e desta sobre a morfologia das papilas ruminais.

Objetivou-se com o presente trabalho, avaliar o efeito do crescimento e plano nutricional sobre a morfologia do rúmen, retículo, omaso e abomaso, bem como das papilas ruminais em cordeiras da raça Santa Inês.

\section{MATERIAL E MÉTODOS}

O ensaio foi conduzido na Escola de Veterinária da Universidade Federal de Minas Gerais, Belo Horizonte, MG, nas dependências do Departamento de Zootecnia, no Laboratório de Calorimetria e Metabolismo, sendo realizado entre os meses de novembro de 2010 a junho de 2011, seguindo normas em acordo com projeto submetido e aprovado pelo Comitê de Ética e Experimentação Animal da Universidade Federal de Minas Gerais, número de registro CETEA 197/10.

Foram utilizadas 36 fêmeas ovinas (Ovis aries) da raça Santa Inês, desmamadas, com idade de 3 a 4 meses e peso entre 14 e 26 kg. Assim que desembarcaram, as cordeiras passaram por crite- rioso exame clínico, sendo pesadas, identificadas, vermifugadas além de receberem medicamento coccidiostático para controle de endoparasitoses. Fezes foram coletadas para realização de exame coproparasitológico, o qual se repetiu de acordo com a necessidade clínica. Realizado os procedimentos acima, os animais foram alojados aleatoriamente em gaiolas de metabolismo previamente sanitizadas, providas de cocho para alimento, cocho para sal, bebedouro e um conjunto para coleta seletiva de excretas composto por caixa plástica e balde cortado em bisel coberto por tela.

Respeitando-se o mínimo de 15 dias de adaptação à ração experimental, os animais foram então divididos em três grupos de 12 cabeças, utilizando-se como critério para formação dos grupos o peso vivo, condição corporal e fenótipo, na respectiva ordem de importância. Cada grupo foi então destinado a cada peso ao abate, 20,30 ou $40 \mathrm{~kg}$ de peso vivo, sendo redistribuídos em dois planos nutricionais, ad libitum ou restrito. Desta forma, formou-se um delineamento inteiramente casualizado com arranjo fatorial $2 \times 3$ (2 planos nutricionais e 3 pesos ao abate).

A ração experimental foi formulada baseada em estimativa de ganho para $300 \mathrm{~g} /$ dia para cordeiros, obtida pelo modelo SRNS (Tedeschi et al. 2010). A quantidade ofertada foi ajustada semanalmente de acordo com o consumo dos animais alocados no grupo ad libitum, de forma que o consumo médio dos animais não restritos (i.e. ad libitum) por unidade de tamanho metabólico (UTM - Peso vivo elevado à potência 0,75 ) foi multiplicado por 1,15 para permitir $15 \%$ de sobra para os animais deste grupo, e, inicialmente, por 0,85 para obter-se a oferta destinada ao grupo restrito. Desta forma, por exemplo, se o consumo médio dos animais ad libitum do grupo 30 fosse $100 \mathrm{~g} / \mathrm{UTM}$, a oferta individual dos animais restritos do mesmo grupo seria 85g/UTM e dos animais ad libitum seria 115g/UTM. A mudança da dieta foi realizada no mesmo dia das pesagens, para que se atualizasse o peso metabólico das unidades experimentais. A restrição de 15\% inicialmente proposta variou consideravelmente durante o experimento, no intuito de manter o ganho de peso dos animais restritos o mais distante possível dos animais ad libitum, sem, no entanto, provocar perdas de peso no primeiro grupo. 0 valor médio final da restrição em relação ao grupo ad libitum para todos os animais foi de $30 \%$.

0 abate foi realizado sempre em número par de animais, de forma que assim que um animal do grupo ad libitum atingia o peso alvo (i.e. $20,30 \mathrm{ou} 40 \mathrm{~kg}$ ), este era abatido simultaneamente a um animal restrito previamente selecionado, e via de regra, este estava sempre abaixo do peso vivo de sua dupla do grupo ad libitum. Estes animais eram pesados e então encaminhados para sala própria para o abate, afastada dos outros animais experimentais, onde eram insensibilizados em estação, içados pelas patas posteriores e sangrados, através de secção dos grandes vasos do pescoço. Na região da incisão, o esôfago foi amarrado com barbante para evitar saída de líquido ruminal. Realizou-se a evisceração através de corte único na região mediana do abdômen, iniciando-se na região do pubis em sentido ao esterno. As vísceras, órgãos abdominais, torácicos, cervicais (traqueia e esôfago) e língua foram retirados em etapa única e armazenados em caixa plástica para separação em bancada. Os procedimentos com as vísceras iniciou-se com ligadura dupla do trato digestivo nas regiões do cárdia, duodeno proximal e reto. Nas duas primeiras, realizou-se secção do conduto alimentício entre as ligaduras para obtenção do estômago total, composto de rúmen, retículo, omaso e abomaso, devidamente separado do baço e omento. 0 estômago total foi pesado cheio e depois separado por ligaduras nas junções rúmen-retículo, omaso e abomaso, sendo estes pesados cheios e depois vazios. Com o rúmen e retículo, após o esvaziamento de 
ambos, procedeu-se a repleção com água para obtenção do volume visceral. $\mathrm{O}$ enchimento total foi aferido de forma visual pela observação da distensão da parede do órgão. 0 volume de água gasto foi mensurado em proveta de $2 \mathrm{~L}$ para determinação do volume das respectivas vísceras. Feito isto, foram identificados, conforme Getty (1986), os sacos cranial (i.e. átrio do rumen) e ventral (Fig.1), os quais foram amostrados (cerca de $10 \mathrm{~cm}^{2}$ ) para análise de morfologia de papilas. Com o material amostrado do saco ventral e cranial do rúmen procedeu-se a contagem e análise de morfologia das papilas ruminais. Cada fragmento, assim que coletado, foi imerso em solução PBS (tampão fosfato), conforme preconizado por Daniel et al. (2006), onde foi resfriado a $-4^{\circ} \mathrm{C}$ em câmara fria. Para a contagem de papilas, as amostras do saco cranial e ventral de cada animal foram estendidas em bandeja repleta de água, sendo prensadas por um aparato plástico (chapa plana com dimensões de $10 \times 10 \mathrm{~cm}$ ) com um quadrado vazado de área igual a $1 \mathrm{~cm}^{2}$. Com auxílio de uma lupa estereoscópica, contaram-se todas as papilas em que se visualizou a inserção da base dentro do quadrado. 0 objetivo da imersão em água foi permitir a flutuação das papilas e desagregação das mesmas, facilitando a análise. Desta forma obteve-se a quantificação de papilas por $\mathrm{cm}^{2}$. (Esquema representado na Figura 2).

Para as análises morfológicas, doze papilas foram destacadas do tecido com auxílio de pinça anatômica e lâmina de bis-

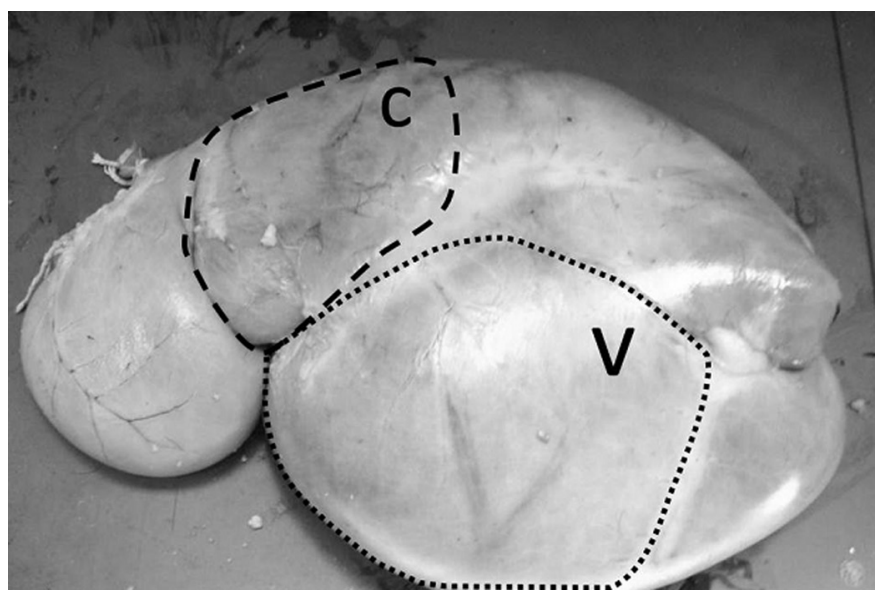

Fig.1. Delimitação ruminal em saco cranial (área tracejada marcada com letra C) e saco ventral (área pontilhada marcada com letra V). turi, sendo transferidas para uma lâmina de microscopia. Essa, ampliada pela lupa estereoscópica, foi fotografada. A imagem gerada para cada fragmento foi então transferida para o computador onde foram analisadas. 0 processamento das imagens foi realizado utilizando-se o programa computacional UTHSCSA ImageTool desenvolvido pela University of Texas Health Science Center de San Antonio, Texas, EUA, e disponível na internet pelo endereço FTP ftp://maxrad6.uthscsa.edu. Este programa utiliza algum item de tamanho conhecido que esteja na mesma imagem (i.e. fotografia), como uma régua ou chapa metálica que se saiba o tamanho, para que informado ao software, por proporção este possa aferir outras estruturas que estejam no mesmo plano da referência.

Para cada uma das doze papilas foram mensurados altura, largura da base e área, conforme demonstrado na Figura 3. 0 valor médio de cada variável obtido a partir da mensuração das doze papilas foi registrado para análise estatística, representando o fragmento como um todo. Para estimativa da espessura média das papilas foi fotografado cada um dos fragmentos imersos em água utilizando-se como referência na imagem uma agulha hipodérmica de $25 \mathrm{~mm}$ de calibre, conforme ilustrado na Figura 2c. 0 valor médio obtido a partir de todos os fragmentos para espessura foi utilizado para todos os animais. Para cálculo da área absortiva por $\mathrm{cm}^{2}$ foi utilizada a equação 1 :

$$
A a b s=((\mathrm{N} \times a) \times 2)-(\mathrm{N} \times(\mathrm{L} \times \mathrm{E}))
$$

onde, Aabs = Área absortiva $\mathrm{cm}^{2} ; \mathrm{N}=$ Contagem de papilas, $\mathrm{N} / \mathrm{cm}^{2}$; $a=$ Área $\mathrm{cm}^{2} ; L=$ Largura da base, $\mathrm{cm} ; E=$ espessura .

As comparações de médias para as variáveis massa e volume das vísceras foi realizada elencando-se teste de Student Newman Keulls (SNK). A análise de variância seguiu o modelo estatístico descrito na equação 2 :

$$
\mathrm{Y}_{\mathrm{ij}}=\mu+\mathrm{R}_{\mathrm{i}}+\mathrm{P}_{\mathrm{j}}+\mathrm{RP}_{\mathrm{ij}}+\mathrm{e}_{\mathrm{ij}}
$$

onde, $\mu=$ média geral da variável analisada $R=$ Efeito do regime alimentar, $i=$ "ad libitum" ou restrito; $P=$ Peso ao abate, $j=20,30$ ou 40; RPij = Efeito da interação do regime i com o peso ao abate j; $e=$ erro residual aleatório.

Para comparação das médias relativas à morfologia e contagem de papilas utilizou-se delineamento em blocos casualizados em arranjo fatorial $(2 \times 3)$, sendo o local de amostragem (saco

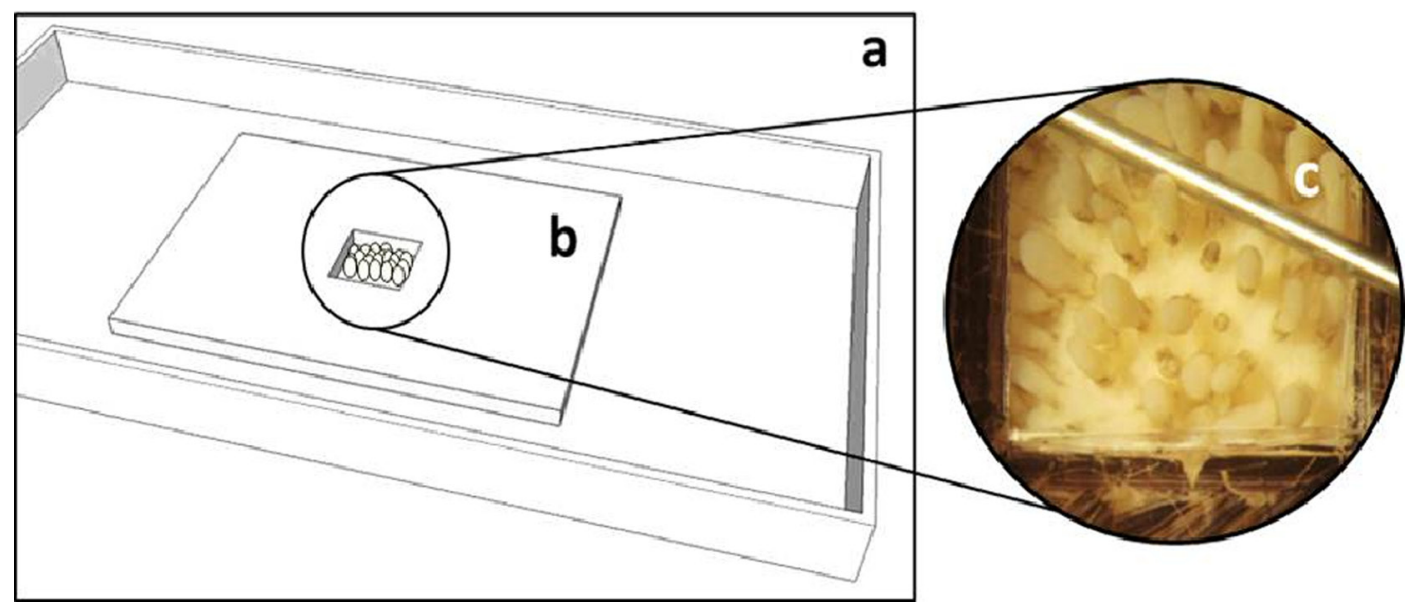

Fig.2. Esquema do aparato (a) para contagem de papilas, placa plástica com quadrado de $1 \mathrm{~cm}^{2}$ vasado (b) e fotografia da imagem da lupa observada durante o procedimento de contagem (c). 


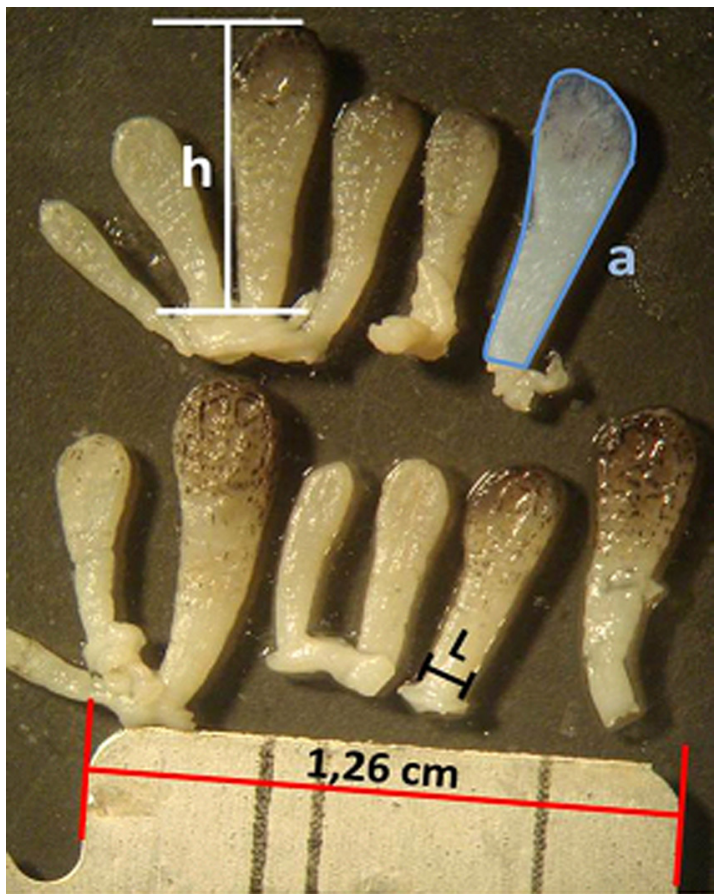

Fig.3. Doze papilas ampliadas e representação gráfica das mensurações realizadas com auxílio do software UTHSCSA ImageTool. h=altura, a=área , L=largura da base e 1,26cm=referência de tamanho conhecido.

cranial versus ventral) analisado como efeito de bloco, e o teste elencado o SNK. A análise de variância seguiu modelo descrito na equação 3:

$$
\mathrm{Y}_{\mathrm{ijk}}=\mu+\mathrm{R}_{\mathrm{i}}+\mathrm{P}_{\mathrm{j}}+\mathrm{RP}_{\mathrm{ij}}+\mathrm{B}_{\mathrm{k}}+\mathrm{e}_{\mathrm{ijk}}
$$

onde, $\mu=$ média geral da variável analisada; $R=$ Efeito do regime alimentar, $i=$ "ad libitum" ou restrito; $P=$ Peso ao abate, $j=20,30$ ou 40; RPij = Efeito da interação do regime i com o peso ao abate j; $B$ = efeito do bloco, $k$ = saco cranial ou ventral; e=erro residual aleatório.

\section{RESULTADOS}

0 efeito do peso ao abate foi significativo para todas as vísceras, tendendo a elevar a massa de todos os compartimentos com o aumento do peso vivo $(\mathrm{P}<0,05)$. No entanto, estatisticamente não se obteve comportamento padrão entre as vísceras, de forma que os compartimentos apresentaram crescimentos distintos. De toda forma, o estômago total aumentou em massa em função do peso vivo ao abate

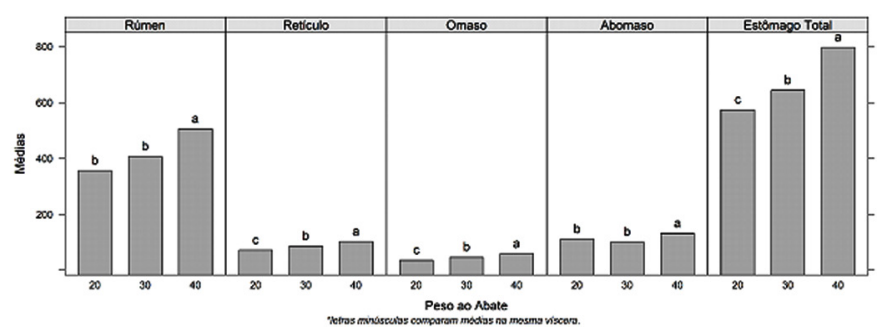

Fig.4. Peso de cada compartimento em função do peso ao abate, 20, 30 ou 40. Letras distintas sobre as barras denotam diferença estatística pelo teste $\mathrm{SNK}(\mathrm{P}<0,05)$.
Quadro 1. Composição percentual da dieta experimental

\begin{tabular}{lc}
\hline Concentrado (Alimentos) & \% na Matéria natural \\
\hline Farelo de Milho & 51,52 \\
Farelo de Soja & 44,87 \\
Fosfato Bicálcico & 0,15 \\
Calcário & 1,84 \\
Bicarbonato & 1,62 \\
Concentrado & 55,44 \\
Volumoso (Feno de Tifton) & 44,56
\end{tabular}

Quadro 2. Composição bromatológica da dieta experimental

\begin{tabular}{|c|c|c|c|}
\hline Nutriente ${ }^{\mathrm{a}}$ & Concentrado & Volumoso & Dieta \\
\hline Matéria Seca (\% da $\mathrm{MN}^{\mathrm{b}}$ ) & 88,23 & 88,84 & 88,50 \\
\hline Matéria Orgânica (\%) & 80,00 & 82,84 & 81,26 \\
\hline Matéria Mineral (\%) & 8,24 & 6,00 & 7,24 \\
\hline Fibra em Detergente Neutro (\%) & 12,42 & 62,18 & 34,59 \\
\hline Fibra em Detergente Ácido (\%) & 5,23 & 31,04 & 16,74 \\
\hline Proteína Bruta (\%) & 31,5 & 10,31 & 22,05 \\
\hline Extrato Etéreo (\%) & 3,74 & 1,93 & 2,93 \\
\hline Energia Metabolizável (kcal/kg) ${ }^{\mathrm{c}}$ & - & - & 2316,03 \\
\hline
\end{tabular}

a Com exceção da matéria seca, todos os outros nutrientes estão apresentados como percentagem da matéria seca; ${ }^{\mathrm{b}}$ Matéria Natural; ${ }^{\mathrm{c}}$ Energia metabolizável média do experimento, sendo a produção de metano estimada pelo modelo descrito por Blaxter \& Clapperton (1965).

(Fig.4), aumentando gradativamente com o aumento do peso. $\mathrm{O}$ abomaso, no entanto, demonstrou comportamento distinto em relação aos demais.

O volume visceral parece acompanhar o crescimento em massa em função do peso ao abate, principalmente o rúmen, sendo este efeito significativo somente nos animais com 40 kg em relação aos animais mais novos, conforme pode ser observado no Quadro 3. Um efeito observado ao nível de significância de $10 \%$ de probabilidade pelo teste SNK foi de que a restrição nutricional elevou o volume do rúmen e retículo em qualquer peso avaliado.

Os dados relativos às análises realizadas nas papilas oriundas do saco cranial e ventral estão dispostos nos Quadros 4 e 5 . 0 aumento do peso ao abate reduziu a quantidade de papilas por $\mathrm{cm}^{2}$ nos sacos cranial e ventral, e aumentou a altura e área das papilas na região ventral. 0 plano nutricional afetou a altura e área papilar nas amostras oriundas do saco cranial, nas quais os animais restritos apresentaram os menores valores para ambas. A largura da base das papilas não foi influenciada pelo local de amostragem, peso ao abate ou plano nutricional. Ressalta-se que a área absortiva não foi influenciada pelos planos nutricionais ou local de amostragem, contudo foi influenciada pelo

Quadro 3. Volume de rúmen (VOLRU), retículo (VOLRT) e rúmen-retículo em Litros (VOLRRT)

\begin{tabular}{ccccccc}
\hline Variáveis & \multicolumn{2}{c}{ VOLRU (L) } & \multicolumn{2}{c}{ VOLRT (L) } & \multicolumn{2}{c}{ VOLRRT (L) } \\
\hline Peso ao abate & Ad libitum & Restrito & Ad libitum & Restrito & Ad libitum & Restrito \\
\hline 20 & $9,78^{\mathrm{Bb}}$ & $10,59^{\mathrm{Ba}}$ & $0,66^{\mathrm{b}}$ & $0,88^{\mathrm{a}}$ & $10,44^{\mathrm{Bb}}$ & $11,48^{\mathrm{Ba}}$ \\
30 & $9,07^{\mathrm{Bb}}$ & $10,47^{\mathrm{Ba}}$ & $0,68^{\mathrm{b}}$ & $0,80^{\mathrm{a}}$ & $9,75^{\mathrm{Bb}}$ & $11,27^{\mathrm{Ba}}$ \\
40 & $12,09^{\mathrm{Ab}}$ & $13,25^{\mathrm{Aa}}$ & $0,76^{\mathrm{b}}$ & $0,86^{\mathrm{a}}$ & $12,85^{\mathrm{Ab}}$ & $14,10^{\mathrm{Aa}}$ \\
C.V. $(\%)$ & \multicolumn{2}{c}{16,26} & \multicolumn{2}{c}{25,83} & 2,66
\end{tabular}

a Coeficiente de Variação. Letras minúsculas distintas denotam diferença estatística entre médias nas linhas para mesmas variáveis pelo teste SNK a $10 \%$ de probabilidade e maiúsculas nas colunas pelo teste SNK a $5 \%$ de probabilidade. 
Quadro 4. Valor de significância para cada uma das variáveis avaliadas relativas às papilas ruminais

\begin{tabular}{|c|c|c|c|c|c|}
\hline \multirow{2}{*}{ Variável } & \multirow[t]{2}{*}{ Local } & \multicolumn{2}{|c|}{ Peso ao abate } & \multicolumn{2}{|c|}{ Regime alimentar } \\
\hline & & S.C. & S.V. & S.C. & S.V. \\
\hline Papilas $/ \mathrm{cm}^{2}$ & $\mathrm{P}<0,1$ & $\mathrm{P}<0,05$ & $\mathrm{P}<0,05$ & ns & ns \\
\hline Altura (mm) & $\mathrm{P}<0,05$ & ns & $\mathrm{P}<0,05$ & $\mathrm{P}<0,1$ & ns \\
\hline Largura da base (mm) & ns & \multicolumn{2}{|c|}{ ns } & \multicolumn{2}{|c|}{ ns } \\
\hline Área $(\mathrm{mm})$ & $\mathrm{P}<0,05$ & & $\mathrm{P}<0,1$ & $\mathrm{P}<0,1$ & ns \\
\hline Área absortiva $\left(\mathrm{cm}^{2}\right)$ & ns & \multicolumn{2}{|c|}{$\mathrm{P}=0,05$} & \multicolumn{2}{|c|}{ ns } \\
\hline
\end{tabular}

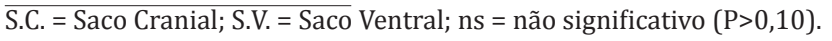

Quadro 5. Papilas por $\mathrm{cm}^{2}$ (PAP), Altura (ALT) e Área (AREA) por tratamento nas amostras dos sacos cranial (SC) e ventral (SV)

\begin{tabular}{lcccc}
\hline Peso ao abate & \multicolumn{4}{c}{ Variáveis } \\
\hline & $\begin{array}{c}\text { PAP S.C. } \\
\left(\mathrm{n} / \mathrm{cm}^{2}\right)\end{array}$ & $\begin{array}{c}\text { PAP S.V. } \\
\left(\mathrm{n} / \mathrm{cm}^{2}\right)\end{array}$ & $\begin{array}{c}\text { ALT S.V. } \\
(\mathrm{mm})\end{array}$ & $\begin{array}{c}\text { ÁREA S.V. } \\
\left(\mathrm{mm}^{2}\right)\end{array}$ \\
\hline 20 & $57,75^{\mathrm{a}}$ & $64,65^{\mathrm{a}}$ & $1,29^{\mathrm{b}}$ & $1,38^{\mathrm{b}}$ \\
30 & $54,3^{\mathrm{a}}$ & $57,5^{\mathrm{ab}}$ & $2,27^{\mathrm{a}}$ & $2,31^{\mathrm{a}}$ \\
40 & $42,8^{\mathrm{b}}$ & $47,5^{\mathrm{b}}$ & $2,13^{\mathrm{a}}$ & $2,47^{\mathrm{a}}$ \\
C.V. $(\%)$ & $27,8^{1}$ & 20,87 & 45,24 & 52,68 \\
Plano Nutricional & \multicolumn{3}{c}{ Variáveis } \\
\hline \multicolumn{5}{c}{ ÁREA S.C. $\left(\mathrm{mm}^{2}\right)$} \\
\hline Ad libitum & ALT S.C. (mm) & \multicolumn{2}{c}{$3,07^{\mathrm{a}}$} \\
Restrito & $2,79^{\mathrm{a}}$ & \multicolumn{2}{c}{$2,27^{\mathrm{b}}$} \\
C.V. $(\%)$ & $2,28^{\mathrm{b}}$ & \multicolumn{2}{c}{46,04} \\
\hline
\end{tabular}

${ }^{a}$ Coeficiente de Variação. Médias acompanhadas por letras minúsculas diferem entre si nas colunas pelo teste SNK, valor P exibido no Quadro 4.

peso ao abate $(\mathrm{P}=0,05)$, sendo maior nos animais com 30 $\mathrm{kg}\left(4,16 \mathrm{~cm}^{2}\right)$ em relação aos demais $\left(3,16 \mathrm{~cm}^{2}\right)$.

\section{DISCUSSÃO}

De Paula (2005), trabalhando com cordeiros Santa Inês, encontrou resposta similar ao deste experimento para o crescimento relativo ao peso de corpo vazio do rúmen e retículo (Peso da víscera/Peso do corpo vazio). Os dados deste autor demonstraram aumento desta variável próximo aos 90 dias, e tendência de manutenção após isto, fato este observado entre o grupo 20, naturalmente mais jovem, e os grupos 30 e $40(\mathrm{P}<0,05)$. Tal ocorrência é natural para ruminantes imaturos em que o desenvolvimento das câmaras fermentativas se dá de forma desproporcional ao crescimento do resto do corpo, desencadeado pelas mudanças na dieta e comportamento ingestivo. Neste momento, coincidente com práticas como o desmame, ocorre rápido crescimento das câmaras fermentativas (rúmen, retículo e omaso) cujo aumento de massa, após esta fase inicial, tende a acompanhar o resto do corpo.

É notório que o epitélio ruminal é sensível à qualidade da dieta, refletindo-se nos tipos de ácidos graxos voláteis formados durante o processo de fermentação (Sakata \& Tamate 1978, 1979). 0 efeito da restrição alimentar quantitativa é, no entanto, menos estudado e resultados obtidos por Scheaffer et al. (2004a) com ovelhas gestantes demonstraram redução do estômago total em função de restrição ingestiva de $40 \%$. No presente estudo, no entanto, este efeito não foi observado, podendo não ter ocorrido em função da menor restrição imposta quando comparada à dos autores supracitados.
Como não houve efeito do regime alimentar sobre a massa destas vísceras, o maior volume deste órgão está provavelmente associado à maior capacidade de distensão de ambas as câmaras (rúmen e retículo) em animais sob alimentação restrita, ou ainda de uma menor densidade da parede ruminal destes animais. Uma forma de avaliar este fenômeno, de forma indireta, é o estudo de papilas no epitélio ruminal. Ressalta-se, no entanto, que de acordo com Harrison et al. (1960), a parede ruminal é composta de partes que possuem crescimentos distintos, o que implica que não necessariamente caso haja, por exemplo, aumento de papilas em função de certo tratamento, toda a parede se comportará da mesma forma. Todavia, Lesmeister et al. (2004) demonstraram haver correlação entre o comportamento das distintas regiões do epitélio ruminal frente a mudanças dietéticas, de forma que amostras do saco cranial e ventral são capazes de representar o tecido como um todo.

Chama-se atenção para o efeito de regime alimentar, que no saco cranial afetou ( $\mathrm{p}<0,1)$ altura e área das papilas, sendo estas menores no grupo restrito. Associado a estes achados, a igualdade no número de papilas entre animais oriundos dos dois planos nutritionais permite inferir que existe menor quantidade de tecido no grupo restrito, corroborando a teoria apresentada anteriormente na discussão sobre volume (Quadro 3), isto é, parece haver uma menor densidade tecidual em animais sob restrição, o que poderia fomentar uma maior elasticidade e maior volume.

0 crescimento das papilas ruminais frente a mudanças dietéticas dá-se basicamente por hiperplasia (Sakata \& Tamate 1979), havendo reposição de células apicais pelas células da base. 0 aumento de suprimento energético, principalmente a partir de butirato (Sakata \& Tamate 1978), eleva rapidamente o crescimento papilar, que pode ser detectado pelo aumento do índice mitótico observado na região basilar das papilas. Estas assertivas corroboram o resultado encontrado neste experimento, em que frente à restrição se observou redução da altura das papilas, bem como da área. Segundo Scheaffer et al. (2004), a demanda desproporcional de energia do trato gastrointestinal em função de seu peso relativo ao corpo faz com que animais sob restrição reduzam a massa destes tecidos. No presente estudo, este fenômeno não foi observado, podendo ser este resultado decorrente da restrição imposta não ter sido limitante para o crescimento e;ou manutenção desses tecidos, uma vez que no quadro geral permitiu leve ganho de peso. No entanto, a redução do tamanho das papilas pode ser uma variável mais sensível do que a massa dos órgãos para alterações dietéticas. Isto porque para manutenção da altura das papilas, demanda-se grande quantidade de energia visto que é um processo de renovação celular contínuo obtido através de mitose, caracterizando processo muito dispendioso, do ponto de vista energético e proteico, cuja intensidade se dá em função do aporte nutricional para essas células, conforme demonstrado por Sakata \& Tamate (1979).

Lesmeister et al. (2004), tentando definir um método para análise e amostragens de tecido ruminal, chegaram à conclusão de que existe elevada correlação entre áreas 
do rúmen quando se observa o efeito de tratamentos como idade, sendo possível que uma única amostra de um mesmo local do rúmen possa representar o desenvolvimento de todo o epitélio ruminal. No entanto, nos dados aqui obtidos, o efeito do local de amostragem foi significativo para a maior parte das variáveis, excetuando-se área absortiva e largura da base. A primeira não foi afetada por nenhum dos tratamentos, aparentando ser a largura da base uma característica fixa da espécie ou genótipo. Similarmente, a área absortiva também não foi afetada pelo local de coleta, todavia as variáveis necessárias para seu cálculo (equação 1) foram influenciadas pela região de coleta, levando a conclusão de que possíveis interações se revelaram, redundando em efeito compensatório.

0 saco ventral foi mais influenciado pelo peso ao abate, sendo altura e área menores para os animais mais leves. Para a variável papilas por $\mathrm{cm}^{2}$ o comportamento foi o inverso, tendo sido observado maiores densidades de papila para os animais dos grupos 20 e 30. Como consequência, foi observado que a área absortiva, independentemente de local, foi maior no grupo intermediário e menor nos grupos dos extremos, 20 e $40 \mathrm{~kg}$. Este resultado é possivelmente um reflexo da dinâmica de crescimento da víscera como um todo, isto é, no grupo 20 a área de absorção por $\mathrm{cm}^{2}$ é menor por que nesta fase embora se possua maior densidade de papilas estas são pequenas e, consequentemente, possuem menor área. Com o crescimento do animal como um todo, a víscera cresce em tamanho (Fig.4), bem como as papilas, obtendo área máxima de absorção, que por fim é reduzida pelo crescimento da víscera não acompanhado de crescimento das papilas, reduzindo-se desta forma a densidade destas. Este último aspecto é confirmado pela redução no número de papilas por $\mathrm{cm}^{2}$ no grupo 40 . Vale ressaltar que embora o número de papilas impacte na área absortiva, a área da papila sempre o faz com maior intensidade, visto que é sempre multiplicada por dois, dada a natureza espacial da variável (equação 1).

A Figura 5 contém as imagens de papilas oriundas de cada região anatômica de amostragem do rúmen para os

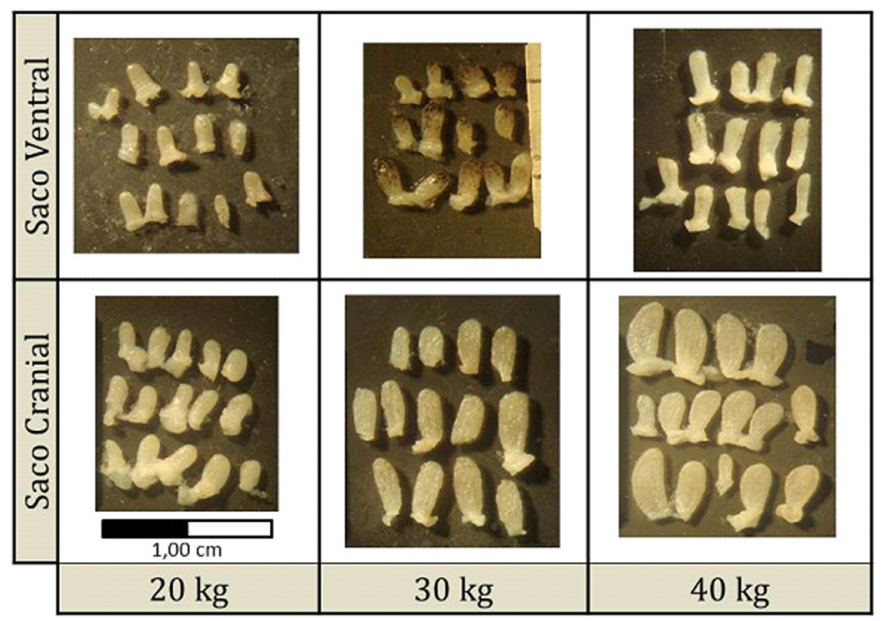

Fig.5. Papilas ampliadas retiradas dos sacos ventral e cranial do rúmen em diferentes pesos ao abate. 0 quadro bicolor no canto inferior esquerdo representa a escala para $1,00 \mathrm{~cm}$. diferentes pesos ao abate. A imagem ilustra bem a diferença observada durante a microscopia entre o tamanho das papilas por local de coleta, i.e., saco ventral ou cranial, sendo notória a superioridade física das papilas extraídas do último saco $(\mathrm{P}<0,05)$.

Embora a restrição não tenha afetado diretamente a área absortiva, a redução da altura e área das papilas provavelmente diminuiu a absorção frente ao grupo não restrito. A falta de significância obtida neste trabalho para a primeira variável pode estar associada à alta instabilidade desta, visto que, para ser obtida, assume o erro das demais. No entanto, essa possível redução pode, na natureza, ser compensada por maiores tempo de retenção da digesta em animais sob restrição. Cavalcanti (2011) observou mudança no comportamento da cinética digestiva dos animais do presente estudo, demonstrando fortes indícios de que os animais restritos apresentaram taxa de passagem ruminal reduzida em relação àqueles de consumo à vontade, corroborando a assertiva anterior. 0 autor demonstrou que estes mesmos animais obtiveram maior digestibilidade da fração fibrosa, o que sugere maior tempo de retenção e aproveitamento do alimento nas câmaras fermentativas, o que em suma pode compensar a redução da área absortiva frente à diminuição das papilas ruminais e manter o aporte nutricional do hospedeiro.

0 plano nutricional bem como o crescimento são fatores determinantes da morfologia do trato digestivo, no entanto, para animais em crescimento, o desenvolvimento corporal parece exercer maior efeito do aquele observado quando animais de maior maturidade fisiológica passam por restrição nutricional.

Agradecimentos.- Ao Núcleo de Extensão e Pesquisa em Pequenos Ruminantes (NEPPER) e à Escola de Veterinária da UFMG. À Coordenação de Aperfeiçoamento de Pessoal de Nível Superior (CAPES), pela concessão de bolsa de mestrado, e ao Conselho Nacional de Desenvolvimento Científico e Tecnológico (CNPq) pelo financiamento do projeto. À Fundação de Amparo à Pesquisa do Estado de Minas Gerais (FAPEMIG), pelo auxílio financeiro para publicação deste artigo.

\section{REFERÊNCIAS}

Baldwin R.L. 2000. Sheep gastrointestinal development in response to different dietary treatments. Small Rumin. Res. 35:39-47.

Cavalcanti L.F.L. 2011. Digestibilidade, cinética e morfologia digestiva em borregas santa inês submetidas à dois planos alimentares. Dissertação de Mestrado em Zootecnia, Escola de Veterinária, Universidade Federal de Minas Gerais, Belo Horizonte, MG. 95p.

Daniel J.L.P., Resende Júnior J.C. \& Cruz F.J. 2006. Participação do ruminoretículo e omaso na superfície absortiva total do proventrículo de bovinos. Braz. J. Vet. Res. Anim. Sci. 43:688-694.

De Paula O.J. 2005. Desempenho e desenvolvimento dos órgãos digestivos de cordeiros Santa Inês, alimentados com dietas contendo diferentes níveis de fibra. Tese de Doutorado, Universidade Federal de Lavras, Lavras, MG. 184p.

Getty R. 1986. Anatomia dos Animais Domésticos. 5a ed. Guanabara Koogan, Rio de Janeiro. 2000p.

Harrison H.N., Warner R.G., Sander E.G. \& Loosli J.K. 1960. Changes in the tissue and volume of the stomachs of calves following the removal of dry feed or consumption of inert bulk. J. Dairy Sci. 43:1301-1312.

Lane M.A. \& Jesse B.W. 1997. Effect of volatile fatty acid infusion on development of neonatal sheep rumen epithelium. J. Dairy Sci. 80:740-774.

Lesmeister K.E., Tozer P.R. \& Heinrichs A.J. 2004. Development and 
analysis of a rumen tissue sampling procedure. J. Dairy Sci., 87:13361344.

Macedo Júnior G.L. 2008. Exigências nutricionais de ovelhas gestantes da raça Santa Inês. Tese de Doutorado em Zootecnia, Escola de Veterinária, Universidade Federal de Minas Gerais, Belo Horizonte, MG. 291p.

National Research Council - NRC. 2007. Nutrient requirements of small ruminants. 362p.

Sakata T. \& Tamate H. 1978. Rumen epithelial cell proliferation accelerated by rapid increase in intraruminal butyrate. J. Dairy Sci. 61:1109-1113.

Sakata T. \& Tamate H. 1979. Rumen epithelium cell proliferation accelerated by propionate and acetate. J. Dairy Sci. 62:49-52.

Scheaffer A.N., Caton J.S., Redmer D.A. \& Reynolds L.P. 2004a. The effect of dietary restriction, pregnancy, and fetal type in different ewe types on fetal weight, maternal body weight, and visceral organ mass in ewes. J. Anim. Sci. 82:1826-1838.

Scheaffer A.N., Caton J.S., Redmer D.A., Arnold D.R. \& Reynolds L.P. 2004b. Effect of dietary restriction, pregnancy, and fetal type on intestinal cellularity and vascularity in Columbia and Romanov ewes. J. Anim. Sci. 82:3024-3033.
Scocco P., Ceccarelli P., Gatti R. \& Catorsi A. 2007. Use of a geographic information system to evaluate morphometric variations of rumen papillae related to diet and pasture vegetative cycle. Vet. Italiana 43:425429.

Sutton J.D., McGilliard A.D. \& Jacobson N.L. 1963a. Functional development of rumen mucosa. I. Absorptive ability. J. Dairy Sci. 46:426-436.

Sutton J.D., McGilliard A.D., Richard M. \& Jacobson N.L. 1963b. Funcional development of rumen mucosa. II. Metabolic activity. J. Dairy Sci. 46:530-537.

Tamate H., McGilliard A.D., Jacobson N.L. \& Getty R. 1962. Effect of various dietaries on the anatomical development of the stomach in the calf. J. Dairy Sci. 45:408-420.

Tedeschi L.O., Cannas A. \& Fox D.G. 2010. A nutrition mathematical model to account for dietary supply and requirements of energy and other nutrients for domesticated small ruminants: The development and evaluation of the small ruminant nutrition system. Small Rumin. Res. 89:174184.

Widdowson E.M. 1980. Definitions of Growth, p.1-10. In: Lawrence T.J. (Ed.), Growth in Animals. Butterworths, London. 